\title{
DON JUAN CORTÉS, CACIQUE DE SANTA CRUZ QUICHÉ ${ }^{1}$
}

\author{
Por Pedro Carrasco \\ University of California, Los Angeles
}

En su famosa obra sobre los señores de la Nueva España, Alonso de Zorita describe la lastimosa situación de los caciques de Uttatlan o Santa Cruz Quiché sucesores de los reyes quichés:

... yo vi los que estaban a la sazón por señores en el pueblo que llaman de Utlatlan, de quien toma nombre toda la provincia, tan pobres y miserables como el más pobre indio del pueblo, y sus mujeres hacían las tortillas para comer, porque no tenían servicio ni con qué lo mantener, y ellos traían el agua y leña para sus casas. El principal de ellos se llamaba D. Juan de Rojas, y el segundo D. Juan Cortés, y el tercero Domingo, pobrísimos en todo extremo: dejaron hijos todos paupérrimos y miserables y tributarios, porque a ninguno excusan de ello, como ya se ha dicho (Zorita: p. 204).

Estos datos se refieren a los años en que Zorita fue oidor de la Audiencia de Guatemala, es decir de 1553 a 1555 . Se podría pensar que se extinguía la nobleza quiché. Sin embargo existen varios documentos que demuestran que los caciques de Santa Cruz mejoraron su situación en años posteriores.

Ximénez extiende la historia de los caciques quichés hasta la época en que escribía su crónica, a principios del siglo dieciocho:

El décimo tercero Rey Quiché se llamó Tecumtepepul que ya está dicho que se llamó Grandeza amontonada y fue el que reinó (si se puede llamar reinar debajo de tan duro yugo como le pusieron) después que fue quemado su padre por la traición que tenía dispuesta contra los españoles, como se dirá después. Éste tuvo

1 La recopilación de materiales en los archivos y bibliotecas de Guatemala y Estados Unidos fue realizada con ayuda de la Wenner-Gren Foundation. En España conté con el apoyo del American Council of Learned Societies. 
dos hijos que se bautizaron y el uno se llamó don Juan de Rojas y el menor don Juan Cortés, y tocándole al señor don Juan de Rojas el Reino, mandó su Majestad que se le asignase una renta cuantiosa para que pasase con la decencia que pedía su real persona, concediéndole muchos privilegios que cuando bajare a Guatemala se le pusiese palacio y despensa a costa de Su Majestad; y que si asistía en público con su audiencia Real tuviese su asiento inmediato a su Presidente de sala, atendiendo su Majestad a su nacimiento y al derecho natural que tenía a su Reino, mostrando su Majestad su gran cristiandad en la Cédula que despachó por aquellos tiempos sobre que todos los Caciques y Señores se mantuviesen en sus Señoríos, porque bien sabía Su Majestad que no podía despojarlos sin causa muy grave del Señorío que la naturaleza le dio. Pero los señores ministros poco cuidaron de eso porque solo prevalecía la tiranía, y tanto, que hasta una porción que tenía de esclavos se los querían quitar, lo cual pleitearon y vencieron el pleito en contradictorio juicio contra el Rey; y eso es lo único que hoy tienen de rentas sus descendientes, cuya línea se conserva en el pueblo de Santa Cruz del Quiché $\tan$ retirados que ni memoria hay de ellos ni se hace...

Siendo aqueste caballero [Don Antonio de Ovalle] Corregidor de Sololá, en cuya jurisdicción cae el pueblo de Santa Cruz del Quiché, donde están los descendientes de los reyes que he dicho, su antecesor en el oficio había mandado que pagasen tributo acudiesen a los tequios que acude la gente más vil sin más motivo que darle gana. El pobre sin recurso sufrió y toleró tanto ultraje, hasta que encontrando este caballero don Antonio en el oficio, ocurrió a él y le pidió que pasase los papeles de sus privilegios y los viese para que enterado de su contenido le atendiese y se les mandase guardar. Esto debió ser a hora que el tal Caballero estaba acostado, porque tomándolos y diciendo que los vería, estuvo aguardando el tal señor la resulta. Metido que los hubo debajo de su colchón se olvidó de tales papeles y estuvieron allí. mas el caballero siempre que se acostaba dos o tres días que tuvo allí los papeles, no podía tomar sueño, sintiendo como ruido debajo de la cama. De este modo pasó todo aqueste tiempo sin dormir y si acaso empezaba a dormitar, le parecía que lo despertaban. Entró en gran ciudad de algún mal, hasta que acordándose de los papeles que allí tenía los sacó y los vio y despachó al tal Señor, y de allí adelante no sintió otra cosa y durmió bien.

(Ximénez: r, pp. 79-80).

Los archivos de España y Guatemala conservan varios documentos que añaden detalles valiosos a lo esbozado por Ximénez. La documentación principal se refiere a Don Juan Cortés. Era éste nieto de Oxib Queh (3 Venado, en mexicano Yey 
Mazatl), quien junto con Beleheb Tzi (9 Perro) eran los reyes quichés, el Ahpop y el Ahpop Camha, a la llegada de los españoles (Popol Vuh: p. 259). Hijo de Oxib Queh, según el documento transcrito a continuación, fue Don Juan Chicuey Quiahuitl, cuyo hijo fue Don Juan Cortés. Chicuey Quiahuitl, 8 Lluvia (su nombre quiché sería Vahxaqui Caok) debe ser el nombre calendárico de Tecum o de Tepepul, el Ahpop y el Ahpop Camha que sucedieron a los anteriores. Se refiere a él el Memorial de Sololá cuando dice que el día 13 Ganel (26 de mayo de 1540) Pedro de Alvarado mandó ahorcar al Ahpoçotz'il Cahi Ymox junto con Quiyavit Caok. (Memorial de Sololá: p. 137).

Don Juan Cortés debió nacer hacia 1530 puesto que según un padrón de 1592, tenía entonces más de 60 años (AGG-Leg. 205, Exp. 4985). En 1557, -se dice entonces de él que era mozo- hizo un viaje a España del cual nos da noticias un par de reales cédulas. Son las siguientes:

Presidente e oidores de la nuestra audiencia real de los confines.

Don Juan Cortés cacique de Utlatlan y de todos sus pueblos y sujetos hijo legítimo que dizque es de Don Juan Chicueyquiagut y nieto de Yeymazatl me ha hecho relación que siendo los dichos sus padre y abuelo señores de la dicha provincia de Utlatlan y teniéndola y poseyéndola entró en ella Don Pedro de Alvarado y sus capitanes y la conquistaron juntamente con la provincia de Guatimala y que el dicho Don Pedro de Alvarado había quemado a su abuelo porque no le daba oro y muerto que fue el dicho Don Pedro y sus lugartenientes despojaron al dicho Don Juan Chicuetquiagut casi de toda la dicha provincia y que había hecho muchos repartimientos de ella en los españoles que con él iban y dividió los pueblos y que así cada uno de los encomenderos hicieron y nombraron cacique a los indios que les parecian y de quien mejor se podían aprovechar y que como murió el dicho su padre y él había quedado muchacho no le habían querido obedecer ni tener por señor y cacique de la dicha tierra como lo habían sido todos sus pasados y que aunque el lo ha pedido los encomenderos de los dichos pueblos lo defendían que no había de ser señor de tantos pueblos ni le habían de obedecer y que ha requerido muchas veces a las justicias de esa dicha provincia para que lo provean las cuales no lo han querido proveer en lo cual recibía mucho agravio y notorio daño y que por esta causa vivía muy alcanzado y necesitado y me suplicó que pues Nos no éramos servido que ningún fuese despojado ni quitado de su cacicazgo vos mandase que le metiésedes en la posesión de la dicha provincia de Utlatlan y le restituyésedes 
el señorío y cacicazgo de ella y de todos sus pueblos y sujetos según y de la manera que lo habían tenido y poseído el dicho su padre y abuelo o como la mi merced fuese. Lo cual visto por los del nuestro consejo de las Indias fue acordado que debía mandar esta mi cédula para vos e yo lo tuve por bien porque vos mando que veáis lo susodicho y llamadas todas las partes a quien tocarse hagáis e administréis sobre ello entero y breve cumplimiento de justicia de manera que las partes le hayan y alcancen y por defecto de ella no tengan causa ni razón de se nos venir ni enviar a quejar sobre ello. Fecha en Valladolid a 30 de noviembre de 1557 años. La princesa. Registrada de Ledesma, señalada de Virviesca, Don Juan Villagómez.

Presidente e oidores de la nuestra Audiencia Real de los confines.

Por parte de Don Juan cacique de Ultlatlan que es en esa tierra me ha sido hecha relación que viniendo él a estos reinos a pedir justicia de agravios y despojos que dice habérsele hecho fue robado de franceses para el cabo de Santa María y le tomaron las escrituras y todo cuanto traía y que agora viéndose perdido y pobre quiere volverse a esa tierra y porque yo acatando su pobreza y necesidad y el daño que ha recibido de los dichos franceses tengo voluntad de le mandar favorecer y hacer merced en lo que hubiese lugar por ende yo vos encargo y mando que tengáis por encomendado al dicho Don Juan cacique y en lo que se le ofreciere le ayudéis y favorezcáis y hagáis la merced que hubiese lugar que en ello seré servido. Fecha en Valladolid a 30 de noviembre de 1557 años. La princesa. Registrada de Ledesma, señalada de Virviesca, Sarmiento, Villagomez.

(AGI - Guatemala 386. Libro de Reales Cédulas, 1551-1560.)

Según estas cédulas el trato que recibió Don Juan Cortés en España fue el acordado a los indios que directamente presentaban sus demandas en la corte: recomendarlos a las autoridades americanas y remitir a éstas la decisión del asunto.

Desgraciadamente no han sobrevivido, que sepamos, las escrituras con que Don Juan Cortés salió de Guatemala ni la relación que presentó al rey. Sin embargo hay noticias muy importantes acerca de sus pretensiones en una carta de Fr. Pedro de Betanzos escrita al rey el día de Navidad de 1559. Trata esta carta de varios asuntos de Guatemala; en un párrafo informa del regreso de Don Juan Cortés - tal vez con una provisión más firme que las reales cédulas transcritas, recordemos los privilegios de Don Juan de Rojas de que habla Ximénez- y al final añade un parecer en 13 puntos acerca de la solución que se debía dar a sus demandas. Escribió Betanzos: 
De acá fue un indio dicho Don Juan Cortés en compañía de un padre dominico el cual trajo una provisión en la cual dice que se le den los pueblos y señoríos que su padre tenía de antes. Yo no sé quién tal pidió y cómo tal se proveyó porque es contra Dios y contra la Corona Real de España. Es el caso que está en este distrito que es una provincia que se dice la nación utateca en la cual hay veinte o treinta pueblos el uno de los cuales era más preeminente porque de allí descendían todos los demás y antes que esta tierra se ganase estaban algunos de los otros muy más prósperos en gente y en poder por ser más guerreros contra otras naciones y éstos como verá Vuestra Majestad por unos trece artículos que aquí van insertos cómo todos juntos y cada uno por sí concluyen que todos estos pueblos no eran tributarios al pueblo de Utatan donde este mozo es que pide a los demás que no tenían sino como eran todos parientes y de una nación y por vía de amistad se hacían servicios unos a los otros y después que Vuestra Majestad tomó en su Corona Real estos reinos de cuarenta años a esta parte no ha habido más este reconocimiento sino cada pueblo ha estado y está quieto con sus principales y caciques y agora que vino esta provisión el Licenciado de Landecho ha querido favorecer este mozo y ha venido a tanto que están todos aquellos pueblos de aquella provincia muy desasosegados por esta novedad tan grande que ya dicen que Vuestra Majestad no es señor de aquella provincia ni la ha de mandar su Real Audiencia sino el dicho Don Juan. Hallámonos los religiosos en esto muy confusos porque no podemos ejercitar nuestro oficio del Evangelio como hasta aquí hemos hecho por esta alteración que de pocos días acá ha habido. Suplico a Vuestra Majestad mande ver los sobredichos artículos que para esto envío a Vuestra Majestad y visto mande proveer de manera que la tierra esté asosegada y no haya otro en ella sino Vuestra Majestad pues la tiene con buen título y así lo sentimos acá los religiosos que Vuestra Majestad está jurado por Rey en estos reinos y aunque no fuese más que por dos cosas que sustenta Vuestra Majestad en estas partes que es el Evangelio de Jesucristo y la administración de la justicia allende de otros muchos bienes que hallamos que se ha hecho la tiene Vuestra Majestad muy justamente y con muy buen título y es Rey de estos reinos de la Indias.

Acerca de lo que pide Don Juan Cortés a los pueblos de Quetzaltenango, Totonicapa, Estalavaca, Çapotitan, Cicicaztenanco, Çaqualpa, Oçumacinta con los demás a ellos sujetos y de la nación utateca se responde que no le conocen por señor ni por tal le han tenido ni tienen ellos ni sus antepasados por las razones siguientes.

La primera razón es porque los señores de Utatan donde este Don Juan es señor y sus antepasados lo fueron nunca tuvieron señorío sobre los dichos pueblos mas de un reconocimiento de parentesco que les tenían por ser todos de unos linajes donde todos procedían los cuales se llaman Cavec y Ninhaib, Ahauqui- 
che, Caleçaquic de los cuales descendían los de este pueblo de Utatan y los demás pueblos sobredichos.

La $2^{a}$ es que si algún señorío se prueba que los sobredichos tenían a Utatan o reconocimiento era por razón del culto divino que allí tenían lo cual cesando por la ley de Cristo cesó aquel servicio porque como dice San Pablo Ad Hebr. 7 cap. Translato enim sacerdotio necesse est ut legis translatio fiat. Porque como este pueblo de Utatan era el principio y fundación de estos linajes venidos a esta tierra de otras partes, así allí como cabeza le tenían respecto a sus dioses los cuales allí dedicaron a los principios por serles favorables y propicios en su jornada o venida a estas tierras a los cuales allí hacian grandes sacrificios y reverencia estos sobredichos pueblos no obstante que tenían otros particulares dioses y templos en sus propios pueblos y por respecto de esto llevaban al dicho pueblo de Utatan grandes presentes y ofrendas a sus dioses y a los ministros de ellos.

La $3^{\mathrm{a}}$ es porque los señores de Utatan eran elegidos por votos por los pueblos sobredichos e no miraban a que fuesen hijos o nietos succesive mas en cada uno de los cuatro linajes sobredichos elegían señor conforme al que mejor les parecía que señorearía y que mejores méritos tenía y este modo de elegir tenían en la cabecera de Utatan y en los demás pueblos sobredichos que cuando moría algún señor se juntaban todos o sus mensajeros por ellos a elegir otro en lugar del que moría por donde se muestra que todos los demás pueblos tenían tanta autoridad como el sobredicho pueblo de Utatan sin los cuales no se podía elegir señor y aunque fuese hijo a nieto si no era elegido e puesto en el señorío por los caciques y principales de los demás pueblos que eran como electores no se tenía por señor.

La $4^{a}$ razón por donde los sobredichos pueblos no reconocen por señores a los de Utatan es que se halla que en tiempos pasados antes que los españoles a estas provincias viniesen hubo un señor en Utatan muy vicioso en vicios abominables y contra natura y no pudiendo su gente sufrirlo quejáronse a los sobredichos pueblos los cuales ellos entre sí hecho concilio van al sobredicho pueblo de Utatan a hacer justicia del tal señor y le mataron y eligieron otro en su lugar por donde se demuestra la antigüedad y autoridad de ellos sin tener reconocimiento de servidumbre al sobredicho pueblo de Utatan.

La $5^{\text {a }}$ razón por donde consta ser estos sobredichos pueblos señores absolutos en sus pueblos cada uno es y se muestra por la costumbre que tenían en las guerras que no se hacía guerra a ninguna otra nación sin el consejo y parecer de todos los sobredichos pueblos y para este consejo se juntaban todos juntos en acuerdo sobre el modo y manera que en la guerra se había de tener aunque al tiempo que los españoles entraron en la tierra se juntaron Queçaltenango, Totonicapa y Estalavaca sin dar parte a Utatan ni a otro ninguno a resistir la entrada a los españoles 
por donde se muestra no tener cuenta con Utatan en reconocerle señorío ni sujección por vía de ser sus tributarios.

La $6^{\text {a }}$ es que ningún indio particular daba tributo ni tenía cuenta con Utatan ni era forzado a ello sino solamente a sus propios señores a quien eran sujetos en cada uno de los pueblos y estos señores no tenían otro reconocimiento de obligación al dicho pueblo de Utatan mas que por la adoración de los ídolos como en Roma el panteón nombrado salvo que como acudían a aquella adoración siempre tenían respeto a aquellos señores de allí como a parientes y amigos suyos a los cuales daban sus presentes y lo mesmo hacían los señores de allí de Utatan con cada uno de los sobredichos pueblos les enviaban sus mensajeros con sus presentes y dádivas por vía de amistad y parentesco y para saber cómo es verdad que allí no había un señor sólo sino cuatro según los cuatro linajes sobredichos donde los unos y los otros descendían cada uno de los cuatro señores hacía sus solemnes fiestas a sus dioses cada año a las cuales convidaban a todos los de su linaje que estaban en los demás pueblos y no a los demás que aunque los llamaran a ello no vinieran por no ser su dios sino sólo de aquel linaje y así se muestra ser cuatro señores en Utatan y no uno y ya que hubiese de venir a que hubiesen de obedecer al sobredicho Don Juan lo cual se prueba no ser así no habían de ser sino los de aquel linaje de donde él desciende que se dice Cavec.

La $7^{\text {a }}$ razón es que de cuarenta años a esta parte que los españoles ganaron la tierra no han tenido ni tienen los sobredichos pueblos al pueblo de Utatan ningún reconocimiento porque cesó allí en aquel panteón su adoración y de los demás demonios que allí había y cesado esto cesaron los presentes y comunicación que tenían con los señores de Utatan el cual pueblo se sujetó a pagar tributo a Su Majestad y ansí los demás pueblos no han reconocido más ni reconocen señorío unos a otros sino sólo uno que es a Su Majestad y ansí están agora ni quieren reconocer a otro ninguno y tienen por cosa muy contra razón que estando ellos en la Corona Real que les pongan otro señor particular que les lleve otro tributo no siendo ellos obligados ni dándoselo en su infidelidad.

La $8^{\text {a }}$ razón es que de los dichos 40 años a esta parte los reinos de Castilla tienen en su Real Corona a esta tierra y jurado por rey de ella al Rey Don Felipe nuestro señor y si algún señorío Don Juan Cortés pretende sobre los dichos pueblos es pretender contra el Rey los cuales tiene Su Majestad en su Real Corona dende los cuarenta años a esta parte y para esto provee presidentes oidores y gobernadores para que rijan y gobiernen los dichos pueblos en justicia y los sustenten en la predicación del Evangelio y ansí de los sobredichos cuarenta años a esta parte lleva Su Majestad los tributos de ellos como vasallos suyos propios y si al dicho Don Juan se admitiese al señorío de ellos sería gran 
detrimento de ellos por la tiranía que en ellos entraría de su parte y pariría de ello perjuicio a la Corona Real en que el dicho Don Juan fuese en ellos señor o otro alguno por él.

La $9^{\text {a }}$ razón que esta tierra es nueva y no muy confirmada en la fe y al presente está quieta y asosegada repartida por señoríos en el modo que los españoles la hallaron y cada señor tiene cuenta con su pueblo o pueblos a él sujetos que gobierna y no tiene más comunicación ni sujeción con los demás señores comarcanos sino cada uno rige y gobierna a su pueblo conforme a las leyes y ordenanzas que el Rey y su Real Audiencia les da y ha acaecido hartas veces que se han querido levantar viendo que los españoles en comparación de ellos eran pocos y a causa de estar los señores y señoríos divididos y repartidos y cada cual por sí sin reconocer uno a otro señorío todos debajo de la Corona Real y con esto nunca se han podido conformar en uno para efectuar su intención y si agora se pusiesen los pueblos sobredichos debajo de un señorío como este mozo pretende poníanse toda la tierra en peligro que por cualquier desabrimiento que se le diese de parte de la Audiencia o por razón de compelerle a la doctrina o por cualquier otra cosa como suele acaecer luego se levantaría y se pondría en efecto su mal propósito e intención porque son gente nueva y muy mutable y muy amigos de novedades y poco han menester para volverlos por su poca estabilidad y consideración.

La $10^{3}$ es que si se admitiese el dicho Don Juan Cortés en el tal señorío habíanse de admitir otros tres o cuatro en aquella provincia que cada uno de ellos tiene el mesmo derecho a otros pueblos que este Don Juan si alguno tiene lo cual es falso y en esta provincia de Guatimala hay cuatro señores guatimaltecas de cuatro cabeceras que aquí había y de éstos han salido treinta o cuarenta pueblos que están repartidos por encomiendas y cacicazgos pueblos ya hechos y formados y si la tal novedad del dicho Don Juan se admitiese con mucho más derecho y razón se habían de admitir los 4 señores guatimaltecas los cuales agora son señores cada uno en su pueblo y como digo si se admiten han de señorear los cuatro señores sobre los pueblos que tengo dicho que descienden de estas cuatro cabeceras y la provincia de Atitlan que son otros dos señores también pedirán lo mesmo de sus sujetos que eran antiguamente los cuales agora poseen cada uno su pueblo y no más y lo mesmo pedirán todos los demás señores de las demás provincias sujetas al distrito de esta Real Audiencia y esto admitido bien se pueden los españoles volver a España y los indios tornar a sus idolatrías y cultos del demonio porque no serán mucha mayor cantidad de españoles de los que hay bastantes a sustentar la tierra.

La $11^{a}$ por donde no se debe admitir en tal novedad al dicho Don Juan en el señorío de los pueblos sobredichos es por la disminución del Evangelio que no podrían los predicadores de 
él administrar la doctrina y cristiandad entre estos naturales con aquella libertad que se requiera que como son gente nuevamente conversos a la fe y de poca capacidad creerán más una palabra que aquél que les diga que cuanto los predicadores les pueden decir y como es nuevo en la fe e hijo de padres idólatras poco habrá menester para tornar a sus ritos y traerlos consigo a ellos como de antes tenían.

La $12^{\text {a }}$ razón es que su Majestad tiene dividida esta tierra y repartida en pueblos por encomiendas en su Real Corona y en sus vasallos y cada pueblo o cacique de él recurre a su encomendero con sus tributos y con él tiene cuenta conforme a como está tasado por la Real Audiencia y ansí cada encomendero tiene cuenta con su cacique o principal del pueblo para lo que le es obligado por su tasación a dárselo e si hubiese uno que a todos los mandase sería gran confusión y los tributos nunca se pagarían a derechas porque tendrían más cuenta con el tal señor a quien todos obedeciesen que no con el Rey ni con sus encomenderos.

La $13^{\text {a }}$ razón por donde no se debe dar el señorío ni es justo de los sobredichos pueblos al dicho Don Juan es porque el Rey y su Audiencia Real serán tenidos en poco de los sobredichos pueblos y por el consiguiente los ministros de la doctrina que como tengo dicho son de poca capacidad y no la tienen en más que en cuanto tienen los ministros de ella e si la Real Audiencia les mandase alguna cosa primero habían de ir a Utatan a tomar parecer y saber del señor de allí si lo harán o no de manera que si el señor de Utatan no quiere que se haga lo que la Real Audiencia mandare no se hará e si sobre el caso les quisieren forzar o castigar vendrá el negocio a rompimiento de tal manera que se levanten que cuando se quiera remediar no puedan e concluyo que lo que se pretende de este negocio e novedad tan injusta e de cualquiera que lo admitiere o favoreciere siento e me afirmo en ello que va directamente contra el servicio de Dios nuestro señor e del Rey.

(AGI - México 280. Hay otra copia incompleta en AHN - Documentos de Indias, 163).

La argumentación de Fr. Pedro de Betanzos es de gran interés en lo referente a las necesidades prácticas de limitar el poder de los caciques para asegurar el dominio español, así como en la justificación del señorío de los reyes de Castilla en las Indias. Comentamos únicamente lo relativo a la organización social y política del reino quiché.

Los cuatro linajes de Utlatlan son los mismos que nombra el Popol Vuh. Eran probablemente grupos patrilineales exogámicos y se relacionan con los primeros pobladores de la tradi- 
ción quiché. Los cauec eran el grupo dominante, acaudillado por Balam-Quiché, cuyo dios era Tohil. Los nihaib, acaudillados por Balam-Acab, tenían como dios patrón a Avilix. Los ahau-quiché, dirigidos por Mahucutah, tenían por dios a Hacavitz (Popol Vuh, 188, 197). Un cuarto caudillo original IquiBalam no dejó sucesión pero en su lugar fue incorporado Qotuhá, primer caudillo de los zaquic. Calezaquic en la carta de Betanzos es realmente el título del señor zaquic, Galel-Zaquic. (Popol Vuh, p. 246; título de Totonicapán: pp. 227, 235.)

Estos linajes no constituían toda la población quiché; eran únicamente una de las tres partes de los quiche-vinak; las otras dos, los tamub y los ilocab, tenían una organización interna en linajes semejante a la de los quiché propiamente dichos. Cada uno de los linajes estaba representado en las diversas poblaciones quichés. ${ }^{2}$ Es notable la importancia de las grandes ceremonias religiosas como fuerza de cohesión de los linajes dispersos en distintos pueblos. Las ceremonias son la ocasión para la venida a Utlatlan de los miembros del linaje y el envío de presentes.

Esta dispersión de los cuatro linajes presenta una situación semejante a la del Acolhuacan en el Valle de México donde todos los grupos étnicos que constituían el reino estaban representados en cada uno de los señoríos (Torquemada: ı, p. 89).

Los distintos señoríos quichés formaban una unidad, bajo la supremacía de la ciudad original Gumarcah o Utlatlan, que también se puede comparar con el Acolhuacan o con los grupos de señoríos dependientes directamente de México o de Tlacopan. El parecer de Betanzos menciona nada más siete pero las fuentes quichés proporcionan varias otras listas, cuyo análisis requiere trabajo aparte, que nos dan una idea bastante completa de la extensión y estructura del dominio quiché.

El sistema de sucesión de los señores quichés también recuerda a uno de los dos tipos que prevalecían en el centro de México, el practicado por los tenochca: el sucesor es elegido por una asamblea de notables de entre los parientes de rango adecuado del antecesor. Varias fuentes antiguas describen la instalación de un cacique y los símbolos de su oficio. Sentaban al nuevo cacique en un banco, le sahumaban con incienso y le ungían con ciertas pinturas. El banco es uno de los símbolos

2 Discuto este tema en más detalle en un estudio que todavía no publico
(Carrasco, Ms.). 
del oficio, como trono en castellano. En un diccionario leemos cómo los señores de los pueblos eran confirmados por los señores de Santa Cruz.

qhacat, el asiento de palo o banquito o silla muy sahumada que usan los indios cuando hacen una cabeza del pueblo. Y en quiché cuando muere alguno de estos cabezas avisan a Santa Cruz del Quiché y viene uno a dar la posesión a uno de los principales que ya ellos conocen por sus sobrenombres y a esta silla llaman qhacat tem.

tem, la viga para sustentar $o$ asiento, tem qhacat, ru tem qhacat ka nima ahaual Dios, el asiento o trono de Dios, que es un banquillo que les daban y en él se sentaban en señal que los hacían cabeza del calpul que era de grande autoridad y cuidado que los sahumaban... (Vico, s.v. qhacat, tem).

Vuelto a Guatemala, don Juan Cortés disfrutó de autoridad suficiente para participar en el nombramiento de algunos caciques de los pueblos quichés. El título de Izquin-Nehaib (1558) y el título de los indios de Santa Clara (1583) son testimonios firmados por don Juan Cortés y otros caciques, de las tierras de pueblos quichés y títulos de sus señores (Recinos: pp. 93, 97, 103, 115, 173).

Los cuatro señores guatemaltecos, es decir, cakchiqueles, que ocupaban una situación semejante a la de los quichés, se mencionan en las fuentes cakchiqueles y los cuatro linajes correspondientes eran xahil, zotz'il, tukuché y ahraxonihay (probablemente una subdivisión akahal). De modo semejante los dos grupos de Atitlan eran los tz'iquinahay y los tz'utuhil.

Hay también documentos que muestran que don Juan Cortés así como el otro cacique cauec, don Juan de Rojas (o Rosas), y después de ellos sus descendientes, conservaron durante la época colonial el título de cacique, la exención de tributos, sus tierras y siervos.

En la Guatemala prehispánica los caciques tenían tierras cultivadas por siervos semejantes a los mayeques de México. Las Casas, al describir el sistema tributario, dice:

Tenían también los señores sus tierras que llamaban realengas, que arrendaban a los que eran pobres, por muy poca renta; en cierta parte dellas tenían los señores sus esclavos casados, los cuales servían con tributo en sementeras y leña y tea de pino para se alumbrar. (Las Casas: p. 622). 
Y Zorita quien nos ha dejado la mejor descripción de los mayeques de México, reconoció la misma institución en Guatemala, región que conoció bien durante sus visitas como oidor a los pueblos de indios:

$\mathrm{Y}$ en Tecpan Guatimala, que es un pueblo muy principal junto a Guatimala, conocí yo a un Señor que había sucedido a un su hermano; y era vivo y yo le conocí, un hijo del Señor ya difunto, e tenía unas tierras e mayeques que habían sido del patrimonio de su padre, y el tío tenía el señorío; pero también decían que se había hecho esto porque el hijo del Señor era ciego, y puso en el cacicazgo al hermano, el que gobernaba aquella sazón. (Zorita: p. 76).

El nombre quiché de estos siervos era nimak achi. En una carta al rey del 15 de junio de 1595, el fiscal Tomás de Espinosa de la Plaza escribe:

Los caciques del pueblo de Santa Cruz Utlatlan y sus sujetos en su gentilidad tuvieron muchas guerras con sus vecinos. A los que de ellos cautivaban hacían esclavos y por esta razón los llamaban nimacachies y hoy les dura este nombre a los descendientes de estos cautivos, pero luego se concertaban los caciques con estos vencidos y les daban la libertad con que se quedasen en sus tierras y les pagasen cierto tributo ellos y los que de ellos procediesen. Este tributo y pecho han cobrado y cobran hasta hoy los caciques de los dichos indios nimacachies y los oidores que han visitado aquellas provincias han conservado los dichos caciques en la posesión de este tributo y en ella también han sido amparados por esta Audiencia. Yo he vuelto sobre este pleito pareciéndome que con este tributo duran entre estos naturales vestigios de las servidumbres bárbaras reprobadas por Vuestra Majestad y que implica contradicción que del tributo formal que a Vuestra Majestad como a su rey universal deben los indios lleven los caciques parte, mayormente que a estos caciques les acuden todos los indios con los servicios que como a tales caciques se les deben que son repararles las casas, hacerles una milpa de maiz, proveerles la casa de agua y leña y darles indios que les sirvan. Concluyóse la causa y la Audiencia la remitió a Vuestra Majestad.

(AGI, Guatemala 10).

El Archivo General de Gobierno de Guatemala guarda varios documentos relacionados con el mismo asunto. Se trata de los nimak achi de los dos caciques de Santa Cruz sucesores del ahpop y el ahpop camha, don Juan Cortés y don Juan de Rojas, cuyo nombre también aparece como Roxas, Rosas o Rosa- 
les. Es conveniente citar las palabras con que se describen estos indios:

En 1574 se les nombra "indios que llaman nimacachies que fueron esclavos de los antecesores de don Juan Cortés y de don Juan de Rosales que les han pagado tributo", y en otro lugar: "los indios que parece que tenían los dichos don Juan Cortés y don Juan de Rojas caciques por sus tributarios que llaman nimacachies por decir que antiguamente eran esclavos de sus pasados".

En 1592 se habla de "Don Juan Cortés cacique de la mitad de la parcialidad de indios nimacachies y don Juan de Rojas cacique de la otra mitad en la provincia de Utlatlan". De don Juan de Rojas se dice que es cacique y "tiene en encomienda la mitad de los indios nimacachies".

Otro documento, de 1596, es una carta presentada por "Ios indios del barrio de nimacachies en este pueblo" (AGG - Leg. 205, Exp. 4985).

Nimak achi, literalmente quiere decir gente grande. Los diccionarios cakchiqueles dan también el significado de extranjero y es un término que fue aplicado a los españoles. Explicando este uso, Coto dice:

Antiguamente llamaban nima achii a cualquiera de otra nación que venía a sus tierras y desde pequeño se criaba con ellos y así han quedado apellidos que se llaman nimakachii. (Coto, s.v. español).

En el diccionario de Barela, Nima achi se define como "cierto chinamital de indios". En Sololá en el siglo xvi había un calpul de Alonso Pérez Nimakachi (AGG - Leg. 2800, Exp. 40485. Ver también Carrasco, 1963), y todavía en la actualidad Nimakachi es un apellido indígena (Tax: pp. 90-96, 130: Termer: p. 374).

Un diccionario que da nimakachi para traducir el español siervo, explica además en otro artículo:

"cativos en guerra y después hacerse vasallos y avecindados, e nimak achi" (Vocabulario español-cakchiquel, s.v. cativo, siervo) .

Esta última definición explica satisfactoriamente el doble significado de extranjero avecinado y siervo. En el centro de México descubrió una situación semejante Fr. Domingo de la Anunciación en su informe escrito en Chalco acerca del sistema 
tributario de la gentilidad: en las tierras de los señores y principales (tecutlalli), acogían éstos "a los que se venían de otros pueblos y provincias huyendo y según el tratamiento les hacían así holgaban o no de les servir y obedecer en lo que les mandaban, y éstos eran los tributarios de los señores y principales". (Epistolario: vir, p. 262.)

Dado este significado de nimak achi como extranjero avecindado, siervo o cliente de los señores, es preciso revisar la traducción de algunos pasajes del Memorial de Sololá en que los traductores han interpretado nimak achii como si fuera nimak achiha, principales, valientes hombres, (Memorial: párrafos $85,183,79-81)$. Es especialmente importante notar el papel de estos nimak achi durante la revuelta de los quiché contra el rey Quicab.

En 1574, los nimak achi de los caciques quichés les hacían milpa, reparaban sus casas y les daban indios de servicio. Hay un padrón de indios nimak achi de esta fecha que comprende 22 parejas de casados con sus hijos solteros. El padrón da también la extensión de tierra que cultivaba el hombre de cada familia que varía de 4 a 8 mecates; uno de ellos criaba gallinas. De todas las mujeres se dice que tejían. Con excepción de seis (de uno se especifica que no era tratante), todos los hombres iban a la costa a comerciar; de tres se dice que iban a traer algodón, de dos que llevaban a vender ropa, uno, con más detalle, la ropa que tejía la mujer. Los indios se quejaron del tributo excesivo que pagaban y consiguieron se les tasara el tributo que debían dar a ambos caciques. (AGG - Leg. 205, Exp. 4985.)

En 1592 los caciques don Juan Cortés y don Juan de Rojas se quejaron de que sus hijos habían sido empadronados como tributarios y pidieron que como descendientes de caciques se les librara del tributo "porque así se guardaba en su gentilidad". Con este motivo hay una lista de indios nobles que incluye a ambos caciques, don Juan Cortés de más de 60 años y don Juan de Rojas de 34 años, así como a sus hijos casados, de los cuales se dice que hacían milpa y criaban gallinas. (AGG - Leg. 205, Exp. 4985.)

En 1603 don Juan de Rosales, cacique de Santa Cruz Utlatlan, pidió ser reservado de tributo. Su padre era Diego Pérez, el cual "fue y era cacique y señor natural de este dicho pueblo porque lo fueron sus pasados ... y era cabeza de calpul de este 
dicho pueblo"; su madre, doña Isabel, "hija de don Francisco Çica que era cacique y señor natural de Yloctenango". Atestiguaron la nobleza de don Juan de Rosales varios indios principales de Santa Cruz: don Juan Gómez, don Diego García, don Lorenzo Gómez y don Gaspar López. (AGG - Leg. 4678, Exp. 40252.)

Un documento más tardío, de 1798 , es la petición de otro indio noble "sobre sus privilegios y pago que solicita se le haga de lo tributado por la nación nimacaché". El solicitante, don Juan de Rojas, o don Juan de Pérez y Rojas, era hijo de Juan Pérez y de doña Isabel Rojas, ésta hija de don Juan de Rojas, cacique. Se dice en la petición que hasta 1692 habían contribuido "a la familia de Rojas de Santa Cruz del Quiché sus tributarios los indios numerados en la parcialidad de Nimacchic". En 1762 se hizo distinto padrón a "la parcialidad de don Juan de Rojas con esta denominación y con la de Nimacchic que es lo mismo". En estos documentos se escribe también nimache, nimacache, nicamache, nimachache. (AGG - Leg. 202, Exp. $4090)$. En este caso la sucesión va por vía femenina de acuerdo con el uso español cuando falta varón, pero en contra de la costumbre de la Guatemala prehispánica donde regía estricta patrilinealidad.

Aunque en referencia a la situación prehispánica se habla de "esclavos", en la época colonial los nimak achi son indios que pagan su tributo y servicios personales al cacique indio y no a la Real Corona. Aparte de su origen histórico, este uso se basa en la decisión de las autoridades españolas. No se les llama renteros en las tierras privadas de los caciques como pasa en México donde es frecuente llamar a los mayeques renteros o terrazgueros, si bien de hecho su situación se basa en la asignación de sus tributos a los caciques. Con estos nimak achi tenemos un caso más que ilustra la gran semejanza entre las instituciones sociales prehispánicas y coloniales de los Altos de Guatemala con las del Centro de México.

\section{BIBLIOGRAFIA}

AgG. Archivo General de Gobierno, Guatemala.

Agr. Archivo General de Indias, Sevilla.

AнN. Archivo Histórico Nacional, Madrid. 
Barela, Fr. Francisco. Vocabulario Cakchiquel. Ms. en el Archivo Histórico del Museo Nacional, México.

Carrasco, Pedro. La exogamia según un documento cakchiquel. Tlalocan, Iv: 193-96. 1963.

- - Territorial and kinship groups in ancient Guatemala. Ms.

Coтo, Fr. Tomás. Vocabulario de la lengua cakchiquel v. guatemalteca. Ms. en la American Philosophical Society, Filadelfia.

Epistolario de Nueva España. 16 vols. México, 1939-42.

Las Casas, Fr. Bartolomé de. Apologética Historia de las Indias. Madrid, 1909.

Memorial de Sololá. Anales de los Cakchiqueles. Título de los Señores de Totonicapán. Edición de Adrián Recinos. México, 1950.

Popol Vuh. Las Antiguas Historias del Quiché. Edición de Adrián Recinos. México, 1947.

Recinos, Adrián. Crónicas Indigenas de Guatemala. Guatemala, 1957.

TAx, Sol. The Towns of Lake Atitlan. Microfilm Collection of Manuscripts on Middle American Cultural Anthropology, núm. 13. Chicago, 1946.

Termer, Franz. Zur Ethnologie und Ethnographie des nördlichen Mittelamerika. Iberoamerikanisches Archiv, Iv: 301-492. 1930.

Título de los Señores de Totonicapán. v. Memorial de Sololá.

Vico, Fr. Domingo. Vocabulario en lengua cakchiquel y quiché. Ms. Bibliotheque National, Paris. Copia en Peabody Museum, Harvard University.

Vocabulario Español-Cakchiquel. Ms. Library of Congress. Washington.

Xıménez, Fr. Francisco. Historia de la Provincia de San Vicente de Chiapa y Guatemala. 3 vols. Guatemala, 1929-1931.

Zorita, Alonso de. Breve y sumaria relación de los señores y maneras y diferencias que habia de ellos en la Nueva España... en Relaciones de Texcoco y de la Nueva España. México, 1941. 